\title{
DETERMINATION BY CALCULATION OF THE LIFESPAN OF INFANTRY ARMAMENT BARRELS AND VERIFICATION THROUGH THEIR RECEPTION FIRING AND OF THE ARMAMENT
}

\author{
Stelian POPESCU \\ "Nicolae Bălcescu” Land Forces Academy, Sibiu, Romania, \\ fam_popes@yahoo.com
}

\begin{abstract}
During normal operation of the weaponry it is important not to cause incidents that put it out of use. For this reason, the article proposes a mathematical instrument for calculating the life of the barrels and a complex methodology for checking by firing them and the armament on which they are mounted. The whole issue is addressed both to the personnel specialized in the design and construction of infantry weapons systems and to the personnel that are in the sphere of their exploitation.
\end{abstract}

KEYWORDS: control, lifespan, firing test, armament adjustment, barrel's operating life.

\section{Determination by Calculation of} the Lifespan of Infantry Armament Barrels

The analytical determination of the relationship between the wear of the infantry weapons barrels and the multitude of factors that determine it is practically impossible. In practice, a series of empirical formulas are used that allow an assessment of the life of the barrels, for guidance (Keresztes, 1999).

The following formulas are more frequently used:

(I) Orlov's formula:

$$
N=\frac{K_{T}}{C_{q}^{x} \times v_{0}^{y} \times d^{z}}
$$

where:

$N$ - the number of shots fired;
$K_{T}$ - the temperature coefficient, which depends on the burning temperature of the powder, the mechanical properties of the barrel's material, including the change of these characteristics as the barrel heats up (for infantry armament $K_{T}=10^{23}$ );

$$
C_{q}=q^{-} d^{3}\left[\mathrm{kgf} / \mathrm{dm}^{3}\right]-\text { the weight }
$$
coefficient of the projectile;

$v_{0}[\mathrm{~m} / \mathrm{s}]-$ initial bullet velocity;

$x, y, z-$ exponents that in a first approximation can be considered: $x=3$; $y=4,5 ; z=2,5$;

$d[\mathrm{~mm}]$ - barrel's caliber. 
(II) The formula used by the English navy:

$$
N=\frac{81444 \times 10^{12}}{d \times(d-5,08) \times v_{0}^{2} \times p_{\max }^{1,7}}
$$

where:

$d[\mathrm{dm}]$ - barrel's caliber;

$p_{\max }\left[\mathrm{kgf} / \mathrm{cm}^{\mathrm{z}}\right]-$ maximum pressure;

$v_{0}[\mathrm{~m} / \mathrm{s}]-$ the initial velocity of the bullet.
(III) Justrow's formula:

$$
N=\frac{\alpha \times \beta \times \gamma \times \sigma_{e} \times \delta \times V_{0}}{d^{2} \times L_{t} \times \sigma_{e C u} \times f}
$$

where:

$\sigma_{e}\left[\mathrm{kgf} / \mathrm{cm}^{\mathrm{z}}\right]$ - the limit of elasticity of the barrel's material;

$\sigma_{e C u}\left[\mathrm{kgf} / \mathrm{cm}^{\mathrm{z}}\right]$ - the elasticity limit of copper $\left(\sigma_{\mathrm{eCu}}=2500 \mathrm{kgf} / \mathrm{cm}^{\mathrm{z}}\right)$;

$\alpha$ - coefficient to be chosen according to the maximum pressure (Table no. 1);

Table no. 1

The value of the coefficient $\alpha$

\begin{tabular}{|c|c|c|c|c|c|c|c|}
\hline $\mathbf{p}_{\max }\left[\mathrm{kgf} / \mathrm{cm}^{2}\right]$ & 1000 & 1500 & 2000 & 2500 & 3000 & 3500 & 4000 \\
\hline$\alpha$ & 1,25 & 0,36 & 0,15 & 0,05 & 0,016 & 0,008 & 0,002 \\
\hline
\end{tabular}

(Source: Keresztes, 1999)

$\beta$ - coefficient to be chosen depending on the caliber (Table no. 2);

Table no. 2

The value of the coefficient $\beta$

\begin{tabular}{|c|c|c|c|c|c|c|c|c|c|c|}
\hline$d[d m]$ & 0,8 & 2,5 & 5 & 10 & 15 & 20 & 25 & 30 & 40 & 50 \\
\hline$\beta$ & 0,03 & 0,13 & 0,30 & 0,60 & 0,86 & 0,93 & 9,94 & 0,95 & 0,97 & 0,98 \\
\hline
\end{tabular}

(Source: Keresztes, 1999)

$$
\gamma=\frac{2 \times \rho}{\pi \times d^{3} \times g}
$$

where:

$q$ [kgf $]$ - bullet weight;

$d$ [dm] - barrel caliber;

$\mathrm{g}\left[\mathrm{dm} / \mathrm{s}^{2}\right]$ - gravitational acceleration;

$\delta[\%]$ - steel specific elongation at break of the barrel; bullet;

$v_{0}[\mathrm{~m} / \mathrm{s}]$ - the initial velocity of the

$L_{t}$ [caliber] - barrel's length;

$f=0,2-$ the coefficient of friction between the bullet and the barrel.

(IV) V.E. Sluhoţki's formula:

$N=k_{1} \times k_{2} \times k_{3} \times k_{C u} \times$

$\frac{d_{b}^{2}-d^{2}}{e^{0,0022 \times p_{0} \times \frac{d}{\epsilon} \times 10^{-3}+0,002 t}} \times \frac{\lambda_{g}+1}{\omega \times v_{0}^{2} \times\left[\lambda_{g} \times\left(\frac{v_{1}}{v_{0}}\right)^{2}+\left(\frac{v_{2}}{v_{0}}\right)^{2}\right]}$

\section{where:} on the caliber;

$k_{C u}\left[\mathrm{kgf} / \mathrm{cm}^{2}\right]$ - resilience of the barrel's material;

$d_{b}[\mathrm{~mm}]$ - maximum barrel diameter;

$t \quad\left[{ }^{0} \mathrm{C}\right]-$ powder combustion temperature;

$\varepsilon$ - the thickness of the thermally affected surface layer;

$p_{0}\left[\mathrm{kgf} / \mathrm{cm}^{2}\right]$ - forcing pressure;

$\omega$ [kgf] - weight of the throwing load;

$v_{1}, v_{2}[\mathrm{~m} / \mathrm{s}]$ - the average velocities of the gases in the connecting cone of the loading chamber during the movement of the bullet in the barrel and respectively during the rear action of the gases;

$$
\lambda_{g}=\frac{l_{g}}{l_{0}}-\text { the relative displacement of }
$$

the projectile in the barrel. $k_{1}, k_{2}, k_{3}$ - coefficients that depend 
Depending on the caliber, $\mathrm{k} 1$ has the values in Table no. 3 .

Table no. 3

The value of the coefficient $k_{1}$

\begin{tabular}{|c|c|c|c|c|c|c|}
\hline $\mathrm{d}[\mathrm{ram}]$ & 50 & 100 & 150 & 200 & 250 & 300 \\
\hline $\mathrm{k}_{1} 10^{-6}$ & 15,8 & 7,10 & 3,40 & 2,00 & 1,96 & 1,93 \\
\hline
\end{tabular}

(Source: Keresztes, 1999)

For a first approximation, the following values of the other parameters are recommended:

$$
\begin{aligned}
& k_{2}=k_{3}=1 ; \\
& \frac{d}{\varepsilon} \times 10^{-3}=1 \text {, for infantery armament; } \\
& \frac{v_{1}}{v_{0}}-\text { is taken from Table no. } 4 \\
& \chi_{a v}=\frac{l_{0}}{l_{c}}, \text { where } l_{c}=l_{r}+0,75 d ;
\end{aligned}
$$

$1_{\mathrm{r}}-$ the actual length of the loading chamber;

$$
l_{0}=\frac{W_{0}}{s}-\text { the fictitious length of the }
$$
loading chamber;

$$
\begin{aligned}
& \frac{v_{2}}{v_{0}}=0 ; \\
& \mathrm{k}_{1}=22,93 \times 10^{6}-\text { for infantry }
\end{aligned}
$$
armament.

Table no. 4

The value of the report $v_{1} / v_{0}$

\begin{tabular}{|c|c|c|c|c|c|c|c|c|}
\hline$\frac{\chi_{\boldsymbol{a} \boldsymbol{v}}}{\lambda_{\boldsymbol{g}}}$ & 3 & 4 & 5 & 6 & 7 & 8 & 9 & 10 \\
\hline 0,6 & 0,227 & 0,256 & 0,243 & 0,233 & 0,223 & 0,215 & 0,211 & 0,208 \\
\hline 0,8 & 0,237 & 0,222 & 0,209 & 0,199 & 0,189 & 0,180 & 0,174 & 0,168 \\
\hline 1,0 & 0,213 & 0,197 & 0,184 & 0,174 & 0,165 & 0,157 & 0,150 & 0,143 \\
\hline 1,2 & 0,196 & 0,180 & 0,167 & 0,157 & 0,149 & 0,141 & 0,134 & 0,128 \\
\hline 1,4 & 0,183 & 0,160 & 0,153 & 0,143 & 0,135 & 0,128 & 0,121 & 0,115 \\
\hline 1,6 & 0,171 & 0,154 & 0,141 & 0,131 & 0,124 & 0,116 & 0,111 & 0,105 \\
\hline 1,8 & 0,161 & 0,144 & 0,131 & 0,122 & 0,115 & 0,109 & 0,103 & 0,098 \\
\hline 2,0 & 0,152 & 0,135 & 0,123 & 0,114 & 0,107 & 0,101 & 0,096 & 0,092 \\
\hline 2,2 & 0,144 & 0,128 & 0,116 & 0,107 & 0,100 & 0,095 & 0,090 & 0,086 \\
\hline 2,6 & 0,131 & 0,116 & 0,105 & 0,097 & 0,091 & 0,086 & 0,081 & 0,077 \\
\hline 3,0 & 0,120 & 0,105 & 0,095 & 0,088 & 0,083 & 0,078 & 0,074 & 0,070 \\
\hline
\end{tabular}

(Source: Keresztes, 1999)

(V) Linte's formula:

$$
N=350 \times \frac{n_{0} \times d^{2} \times \sigma_{r}}{n \times \sigma_{e} \times w}
$$

where: $n_{0}$ - expected firing rate; $n$ - firing cadence achieved; $w=\frac{q \times v_{0}}{2 \times g}(7)$
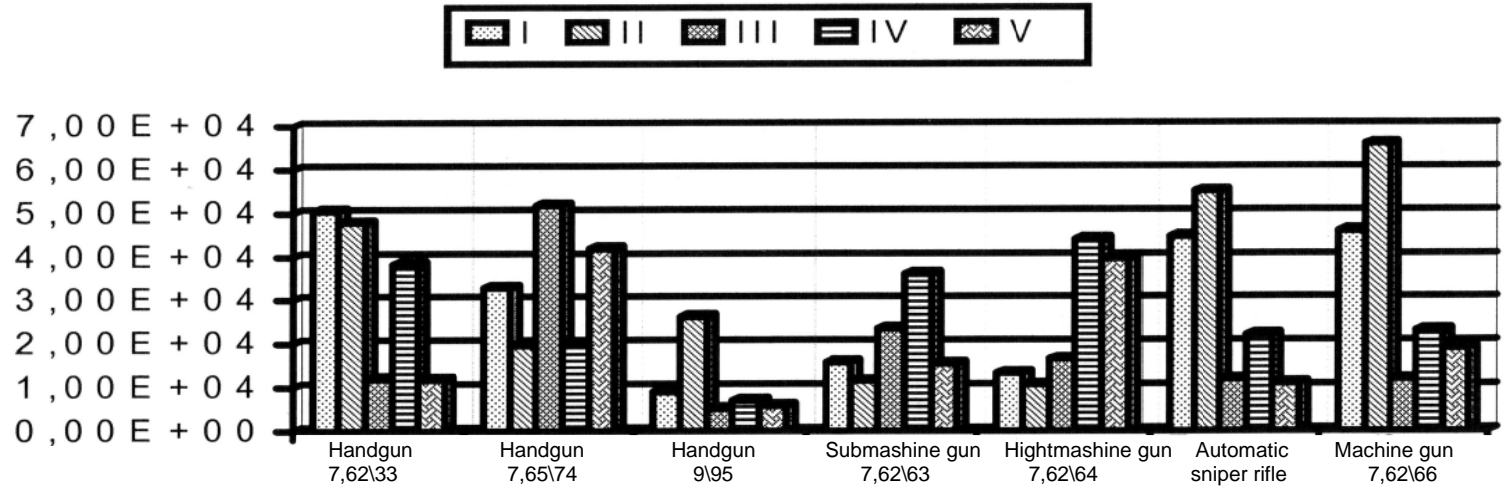
Analyzing the formulas presented above, it is not difficult to notice that some not only do not give satisfactory results, but contradict the experimental data. For example, Justrow's formula shows that the life of the barrel increases as the initial velocity of the bullet increases, and Linte's formula shows that the life of the barrel increases as the caliber increases.

In the specialized works it is considered that the most argued is the formula of V. E. Sluhoţki. However, this formula is difficult to exploit, and the results obtained by applying it are not close to the experimental results (Popescu, 2020).

\section{Verification through Reception} Firings of Infantry Barrels and Armament

In the manufacturing process, the last stage regarding the control of the armament is the execution of firing in order to verify the resistance of the barrel to overpressure; the resistance of the armament as a whole; armament adjustment; checking the functioning of the mechanisms; checking the interaction of the parts; resistance of the barrel and parts to firing with a large number of cartridges (STP-M 040315, 1992).

Basically, the firing check is similar for all categories of infantry weapons. Therefore, below, for example, the checks performed on the 1963, $7.62 \mathrm{~mm}$ submachine gun, are presented.

\subsection{Overpressure Testing of Barrels}

The endurance of the barrels is tested by pulling two "blind" cartridges with an overpressure of $400 \pm 10 \mathrm{MPa}$, in a special device. The barrels are permitted if after firing they correspond to the check with the gauges for the cartridge chamber and the inside of the barrel, as well as if the barrels do not have cracks, swellings and other defects, aspects that are controlled by external examination and with the help of the flaw detector (Mihăilă, 1982).

\subsection{Armament Endurance Test}

After visual and dimensional control of the assembly, according to the control sheets and specifications, the armament is tested by pulling two overpressure cartridges $($ Pmed $=\max .345 \mathrm{MPa}$, Pmin $=\min .310 \mathrm{MPa})$. As a result of these tests, the armament and the barrel must not show mechanical damage, cracks, swelling and other defects.

\subsection{Adjusting the Armament for Normal Firing}

To check the firing of the weapon, 4 cartridges are fired, fire by fire, booster 3 , at a distance of $100 \mathrm{~m}$ in targets where the difference between the control point and the aiming point is $25 \mathrm{~cm}$. Firing is performed with the gun stock fixed on a rigid support and the barrel groove backed on another support.

It is considered that the armament fires normally, if the deviation of the average point of the 4 shots (or three if one is outside the target) from the control point is maximum $5 \mathrm{~cm}$ in any direction, and the trace of the bullets in the target must be included in a circle with a diameter of $15 \mathrm{~cm}$.

If all 4 bullets are not contained in the circle with a diameter of $15 \mathrm{~cm}$, then it is allowed to determine the midpoint at three more grouped bullets, provided that the fourth shot is at a distance greater than 2.5 radii of the circle comprising the three shots, relative to the midpoint of the three grouped bullets.

\subsection{Verification by Firing of the Safe Operation of the Weapon Mechanisms}

The control is done with the bed resting on a shock absorber (whose effort must be $0.8 \mathrm{~N}$ at the preliminary compression of the arch, the rigidity being $120 \mathrm{~N} / \mathrm{m}$ ) or holding it with the hand resting on the shoulder. 
With each weapon 9 cartridges are fired, of which 2-3 are fired with fire and the others in two series of 3-4 cartridges each. With a single magazine, three weapons are tested successively. After the first and second series of 9 cartridges, a practice cartridge is inserted in the magazine. For 9 cartridges fired, no misfires are allowed.

If a miss has been obtained and if after the verification (external appearance, with calibers, the interaction of the parts, etc.) deviations from the specifications are found, the weapon is further tested, with 120 cartridges, using the same magazine. If misfires are obtained in this case as well, the weapon is returned to the manufacturer for repairs.

\subsection{Control Firings to Check the Interaction of the Parts}

From each batch of technically received weapons, before sending them for preservation and packaging, at least 5 pieces $(1.5 \%$ of the lot) are subject to control. With each weapon, 180 cartridges are fired using the magazines intended to complete the received weapons. Misfires are not allowed during the shootings, and in case of their occurrence, the weapon machine is checked and thoroughly verified. If deviations are found, the whole batch is returned to the manufacturer for repair.

If after the remediation there are no deviations from the execution drawings and the specifications, with the weapons for which failures were obtained, 500 cartridge shots are fired. If at least one failure is obtained in this case, it is allowed to increase the number of cartridges up to 2000 pieces.
The batch is considered to meet the conditions, in terms of the interaction of the mechanisms, if for each weapon taken the number of misfires does not exceed $0.2 \%$ of the number of shots fired with that weapon.

In case of unsatisfactory results at the control draws, the causes of the failures are established and the defects in the whole batch are remedied, after which $100 \%$ re-control and the control firing are repeated. If the causes of the failures are not ascertained, a double number of weapons are taken and control firing is carried out under the same conditions. If negative results are obtained in this case as well, the batch is considered unsuitable.

Before the control firing and the firing of 150 cartridges, the gun is cooled of by immersion in water to the level of the magazine. After cooling, the gun is not wiped or greased, but only shaken to remove water drops.

Each time, after cooling, the first 50 cartridges are fired in continuous series, and the rest of the cartridges in short series of 3-5 shots and by firing 5-10 cartridges with each magazine.

The shots are fired by resting the gunstock on the shoulder or on the shock absorber. It is allowed to use a support under the barrel's groove.

\subsection{Control of Interchangeability of} Parts

For the control of interchangeability, 15 weapons are taken (periodically) whose parts are subjected to a detailed control, according to the technology. The weapons taken are subject to control externally, they are weighed and checked using gauges and checkers, and for the $7.62 \mathrm{~mm}$ barrel, the calibers from Table no. 5 are used. 
Table no. 5

Table with calibers and dimensions to be checked at the technical reception of the pipes

\begin{tabular}{|c|c|c|c|}
\hline $\begin{array}{l}\text { Crt. } \\
\text { no. }\end{array}$ & Verification content & Verified size or caliber size & Remarks \\
\hline 11. & $\begin{array}{l}\text { The diameter of the barrel channel between } \\
\text { the grooves }\end{array}$ & $7,62^{+0,06}$ & \\
\hline 2. & $\begin{array}{l}\text { The diameter of the barrel channel between } \\
\text { the gaps }\end{array}$ & $7,92^{+0,076}$ & \\
\hline 3. & The width of the barrel rifling & $3,82^{+0,2}$ & \\
\hline 4. & $\begin{array}{l}\text { Straightness of the barrel channel: } \\
\text { short calibers }(\mathrm{L}=70 \mathrm{~mm}) \\
\text { long calibers }(\mathrm{L}=300 \mathrm{~mm})\end{array}$ & $\begin{array}{l}\text { 1. } \mathrm{d}=7,633 \\
\text { 2. } \mathrm{d}=7,658 \\
\text { 1. } \mathrm{d}=7,587 \\
\text { 2. } \mathrm{d}=7,614 \\
\text { 3. } \mathrm{d}=7,625\end{array}$ & \\
\hline 5. & Cartridge tube chamber diameter & $11,35^{+0,05}$ & \\
\hline 6. & $\begin{array}{l}\text { Diameter in the center section of the first } \\
\text { cone of the cartridge chamber }\end{array}$ & $10,764^{+0,05}$ & \\
\hline 7. & $\begin{array}{l}\text { Diameter and position of the small end of } \\
\text { the first cone of the cartridge chamber }\end{array}$ & $10,17 \mathrm{NT}$ & \\
\hline 8. & $\begin{array}{l}\text { Diameter of the large end of the second cone } \\
\text { of the cartridge chamber }\end{array}$ & $10,12^{+0,05}$ & \\
\hline 9. & $\begin{array}{l}\text { Diameter of the small end of the second } \\
\text { cone of the cartridge chamber }\end{array}$ & $9,09 \mathrm{NT}$ & \\
\hline 10. & $\begin{array}{l}\text { Median diameter of the second cone of the } \\
\text { cartridge chamber and its position }\end{array}$ & $9,43 \mathrm{~T}$ & \\
\hline 11. & $\begin{array}{l}\text { Diameter of the large end of the third cone } \\
\text { of the cartridge chamber }\end{array}$ & $8,74^{+0,05}$ & \\
\hline 12. & $\begin{array}{l}\text { Diameter of the large end of the fourth cone } \\
\text { of the cartridge chamber }\end{array}$ & $8,60^{+0,05}$ & \\
\hline 13. & $\begin{array}{l}\text { Diameter of the small end of the third cone } \\
\text { of the cartridge chamber }\end{array}$ & $8,65 \mathrm{NT}$ & \\
\hline 14. & $\begin{array}{l}\text { Diameter of the small bend of the fourth } \\
\text { cone of the cartridge chamber }\end{array}$ & $7,68 \mathrm{NT}$ & \\
\hline 15. & $\begin{array}{l}\text { Median diameter of the fourth cone of the } \\
\text { cartridge chamber }\end{array}$ & $8,11^{+0,05}$ & \\
\hline 16. & $\begin{array}{l}\text { Diameter of the small end of the fourth cone } \\
\text { at a distance of } 44.7 \text { from the front surface } \\
\text { of the detonator }\end{array}$ & 7,793 NT & \\
\hline 17. & $\begin{array}{l}\text { Coaxiality of the barrel cone and of the } \\
\text { cartridge chamber }\end{array}$ & $\begin{array}{c}7,62 ; 8,60 ; 8,74 ; 10,12 ; \\
11,35\end{array}$ & \\
\hline 18. & Shutter caliber for checking the gun lock & $32,85 \mathrm{~T} ; 33,00 \mathrm{NT}$ & \\
\hline 19. & Gas hole diameter & $3,7^{+0,15}$ & \\
\hline
\end{tabular}

(Source: Keresztes, 1999)

The removable parts and drawings regarding the dimensions, subassemblies of the weapon, established in hardness and other characteristics. To check advance, are checked for correspondence for interchangeability, the parts and with the conditions in the execution subassemblies are mixed, then the weapons 
are reassembled, without the choice or adjustment of the parts, and then examined according to the conditions for the assembled weapon.

The weapons thus assembled are subjected to firing to verify the safe operation and control of the interaction of the parts. If the weapons meet the requirements, shootings are performed to verify the grouping (precision) of shots at a distance of $100 \mathrm{~m}$. The weapon is appropriate if, during the shooting of three series of 20 cartridges each, the average value of the spread within the range and direction does not exceed $20 \times 20 \mathrm{~cm}$ in the case of automatic shooting and $10 \times 10 \mathrm{~cm}$ in case of shooting fire by fire.

The firing is performed from a lying position or from a firing chair, resting the gun stock on the shoulder and securing a support under the barrel groove. In the case of automatic firing, shooting is done in short series of 3-5 cartridges.

\subsection{Testing the Weapon by Firing a} Large Number of Shots

In order to verify as completely as possible the safe operation of the armament and the strength of the parts, a weapon is periodically tested by firing 15,000 cartridges, of which the last 5,000 cartridges for optional control (STP-M 040488, 1996).

The weapon, with its series of magazines, is subjected to the firing test and is fixed on a support provided with a shock absorber. After every 150 cartridges fired, the gun is cooled off in the water, through the barrel, without getting the groove and the barrel guard wet. After each 2500 cartridges fired, the gun is cleaned, the components examined and greased. After each 5000 cartridges fired, the following elements are thoroughly checked and measured: the inside of the T/NT caliber barrel; locking mechanism with shutter caliber; the position of the extractor claw; triggering effort; the loose state of the rod; the condition of the inside of the barrel.
The determination of the grouping of shots is made at the beginning and after firing 10,000 cartridges at a distance of $100 \mathrm{~m}$, as follows:

- Fire by fire, from the lying position and backed or from the firing seat, of 3 series of 20 cartridges each;

- after firing 10,000 cartridges, the scattering radius (within the range and direction) can increase a maximum of twice compared to the scattering radius before firing begins (Popescu, 2019);

- at the first and last 2500 cartridges, the gun is tried with the bayonet.

Before starting the durability tests, the weapon is tested with 30 maneuvering cartridges using the recoil hardener, and after firing 10,000 cartridges, another 150 maneuvering cartridges are fired.

The weapon is considered to have been tested if, after firing 10,000 cartridges, the number of misfires does not exceed $0.2 \%$ and none of its main parts have been damaged.

\section{Conclusion}

The article is intended to be a corollary of the main actions on highlighting the life of the barrels and their firing tests and the categories of infantry weapons on which they are mounted and offer a special perspective on:

$>$ mathematical models for calculating the lifespan of infantry weapons barrels;

$>$ methods of verification by firing, as a guarantee of the safe operation of the armament during operation, in the context in which their application prevents the occurrence of possible incidents, their subsequent manifestation being purely accidental;

$>$ achieving the condition of interchangeability of the parts in the composition of the weapons;

$>$ guaranteeing the resistance of the barrels and armament to normal and overpressure firing. 


\section{REFERENCES}

Keresztes, L. (1999). Tehnologia de fabricație a țevilor de armament. Referat I, Bucharest:Academia Tehnică Militară.

Mihăilă, C. (1982). Procese termodinamice în sistemul gaz - solid și aplicațiile lor în industrie. Bucharest: Editura Tehnică.

Popescu, S. (2019). Sisteme de armament de infanterie - curs. Sibiu: Editura Academiei Forțelor Terestre "Nicolae Bălcescu".

Popescu, S. (2020). Balistică și teoria tragerii cu armamentul de infanterie - curs. Sibiu: Editura Academiei Forțelor Terestre "Nicolae Bălcescu".

STP - M 040315. (1992). Armament de infanterie - Metode de încercări prin trageri la producția de serie.

STP - M 040488. (1996). Armament de infanterie - Metode de determinare a preciziei și stabilității tragerii la încercarea de anduranță. 